\title{
Paulo Freire e a Educação de Jovens e Adultos:
}

\author{
uma abordagem interdisciplinar
}

\section{Paulo Freire and the Youth and Adult Education: an interdisciplinary approach}

\author{
Edgar Pereira Coelho ${ }^{1}$ \\ edgar.coelho@ufv.br \\ Cezar Luiz De Mari² \\ cezar.demari@ufv.br
}

\begin{abstract}
Resumo
Este artigo busca desenvolver a temática da Educação de Jovens e Adultos a partir de Paulo Freire, analisando-a sob o prisma da interdisciplinaridade. As análises resultam de estudos das obras de Freire e aproximações teóricopráticas com experiências vividas e observadas pelos autores. Em foco, elegese o Círculo de Cultura como concepção pedagógica, cujo caráter dialógico e dialético propõe uma mudança profunda no processo da alfabetização de jovens e adultos. A perspectiva freiriana de alfabetização avança sobre a concepção tradicional, apontando a realidade do sujeito como o primeiro passo para a aprendizagem. Assim, a vida, nas suas diversas faces, constitui-se em mediação central para um processo mais avançado de leitura de mundo.
\end{abstract}

Palavras-chave: Círculo de Cultura, EJA, Concepção Pedagógica, Interdisciplinaridade, Processos educativos.

\begin{abstract}
This article aims to develop the thematic of the Youth and Adult Education based on Paulo Freire, analyzing it from the interdisciplinarity perspective. These analysis results from the study of the work developed by Freire and from the theoretical-practical approaches with the observations and experiences of the authors. Focus was given to the Circle of Culture as pedagogic concept, in which its dialogical and dialectical character proposes a profound change in the process of youth and adults literacy. The Freirean perspective of literacy overcomes the traditional concept, pointing the reality of the subject as the first step to learning. Thus, life in its several experiences becomes the central mediation for a more advanced reading of the real world.
\end{abstract}

Keywords: Culture Circle, Youth and Adult Education, Pedagogic Concept, Interdisciplinarity, Educational Processes

\footnotetext{
${ }^{1}$ Professor do Departamento de Educação da Universidade Federal de Viçosa - UFV/MG. Atua na graduação e pós-graduação em educação. Pesquisa a partir dos referenciais freirianos, racionalidades oprimidas. Líder do Grupo de Pesquisa: Educação, meio ambiente e ecopedagogia. Professor de filosofia da educação DPE/UFV.

2 Professor do Departamento de Educação da Universidade Federal de Viçosa - UFV/MG. Atua na graduação e pós-graduação em educação. Pesquisa questões relativas ao conhecimento processos educativos e políticas educacionais. Líder do Grupo de Pesquisa: Educação, conhecimento e processos educativos e do Grupo de Estudos dos Clássicos Contemporâneos em Educação - GECCE. Professor de filosofia da ciência do DPE/UFV.
}

Revista Educação Online PUC-Rio nº 14, p.39-53, ago./dez. de 2013. 


\section{Introdução}

O pensamento freiriano desperta, em cada tempo, novas perspectivas e múltiplas análises, na medida em que seus referenciais contribuem para a atualização do pensamento crítico em diversas áreas do conhecimento. Observamos filósofos, geógrafos, historiadores, profissionais das áreas da saúde, das ciências sociais, ciências sociais aplicadas e outros, utilizando a epistemologia de Paulo Freire como instrumento de análise e da construção de saberes. Para alguns, o foco de seu pensamento encontra-se na Educação de Jovens e Adultos - EJA. Brandão (2005), porém, encarregou-se de apresentar Paulo Freire, o menino que lia o mundo, demonstrando que o seu pensamento não estava restrito à EJA, mas se adequava muito bem aos estudos da infância e adolescência.

O que se denominou inicialmente como método de Paulo Freire, cuja expressão contemporânea mais conhecida é Círculo de Cultura, vem sendo utilizado amplamente nas diversas áreas do conhecimento, inclusive como metodologia de pesquisa. Romão et al (2006) utilizam a denominação de círculo epistemológico para expressar a metodologia de pesquisa que se adequa não apenas às distinções de sua fonte, como remete ao círculo de cultura, mas também, e principalmente, pela consideração dos "pesquisados" como sujeitos da pesquisa. Nesse sentido, Romão et al (2006) preservam o princípio freireano de que todos, no círculo de cultura, são sujeitos que, enquanto pesquisam e são investigados, investigam. É por essa mesma razão, que a expressão o(a) pesquisado(a) é substituída por o(a) pesquisando(a). Os(as) pesquisandos(as) não apenas são objetos da pesquisa, alvos da análise e da enunciação alheia, mas também sujeitos de análise e enunciação.

Professores e alunos se transformam em educadores e educandos, que constroem saberes na troca de conhecimentos. O professor deixa de ser aquele que sabe tudo e passa a ser encarado como quem também aprende. 0 educando descobre que é possível aprender com prazer e compromisso social. Há um apelo de Freire para que não repitamos o que ele fez, mas para que o reinventemos. Nessa direção, buscamos testar essa ideia na realização dos 
Terreiros Culturais e das Trocas de Saberes ${ }^{3}$, que ocorrem na Zona da Mata Mineira, bem como nos trabalhos de ensino, pesquisa e extensão, realizados por um conjunto de educadores e educandos, comprometidos com os princípios freireanos, na Universidade Federal de Viçosa - UFV. Em ambos os projetos, realizamos oficinas denominadas de Instalações Pedagógicas - IP, que consistem na escolha de uma determinada temática com um facilitador e vários outros colaboradores, que apresentam o assunto a partir da contribuição coletiva dos participantes.

Pudemos perceber que qualquer sujeito pode ser facilitador ${ }^{4}$ na IP, desde que o mesmo saiba a técnica, cuja compreensão axiomática consiste no reconhecimento de que a construção coletiva gera conhecimento. No grupo, não há alguém que tudo saiba, mas cada participante pode contribuir com uma parcela do conhecimento, somando e dividindo suas perspectivas teóricopráticas e prático-teóricas ${ }^{5}$. Nesse contexto, discutem-se ideias e práticas, no limite e na condição de cada sujeito ali envolvido. Trata-se de uma atividade que é interdisciplinar por princípio, por abranger as diversas facetas das áreas do conhecimento humano.

Nesse sentido, nosso objetivo com este texto é compreender o caminho teórico-prático realizado por Paulo Freire, em seu trabalho de Educação de Jovens e Adultos, a partir de alguns de seus referenciais, tais como: Educação como prática da liberdade (2000a), Pedagogia do oprimido (2000b), Para trabalhar com o povo (1992), Cartas à Guiné-Bissau (1984) e Cartas à Cristina (1994). Buscaremos focar a EJA, muito embora compreendamos que os princípios gerais adotados para os adultos se adequam ao trabalho com a educação de crianças, levando em conta especificidades educativas, como a idade e a relação cultural de cada grupo humano. Como podemos observar em Brandão (1985), quando escreve sobre o pensador, no livro Paulo Freire, o menino que lia o mundo, e faz uma adaptação da linguagem para as crianças.

\footnotetext{
${ }^{3}$ A troca de saberes se dá dentro do evento denominado Semana do Fazendeiro, que ocorre uma vez por ano no Campus da UFV. Os Terreiros culturais ocorrem nas comunidades nos encontros dos agricultores familiares da Zona da Mata Mineira.

${ }^{4} \mathrm{O}$ facilitador é o que orienta, contribui, coordena, para que se dê um Círculo de Cultura.

${ }^{5}$ Também é possível utilizar o sinônimo práxis, que, na tradição do pensamento dialético, implica em reconhecer a unidade entre teoria e prática. Freire utiliza a concepção de práxis de modo mais intenso na obra Pedagogia do oprimido.
}

Revista Educação Online PUC-Rio no 14, p.39-53, ago./dez. de 2013. 
Já nas primeiras obras de Freire, se fazia presente uma preocupação com a educação dirigida ao público de massa, o que, de algum modo, já demonstrava as possibilidades e diversidades de seu pensamento. Assim, na perspectiva de Freire (2000a):

A educação das massas se faz, assim, algo de absolutamente fundamental entre nós. Educação que, desvestida da roupagem alienada e alienante, seja uma força de mudança e de libertação. A opção, por isso, teria de ser também, entre uma "educação", para a "domesticação", para a alienação, e uma educação para a liberdade. "Educação" para o homem-objeto ou educação para o homemsujeito. (p. 44)

A educação, nesse sentido, aponta para uma radicalidade educativa, em prol de uma real libertação. Uma vez que a população tenha direito ao acesso à educação, o primeiro passo será tomar consciência dessa injustiça social. Para isso, inicia-se uma permanente luta de libertação desse processo domesticador, que propõe uma educação alienante, reificadora, ou, como gostava de dizer Freire, uma "desgentificação".

A educação freireana, em essência, visa a libertar e favorecer a abertura de novos horizontes, no forjar de homens e mulheres sujeitos de sua própria história, o que os capacitariam a serem os construtores de seus próprios caminhos e gestores de suas vidas. A compreensão freireana é a do fortalecimento de sujeitos não sujeitados. Homens e mulheres livres de relações servis, com uma vocação ontológica para serem mais, no sentido de uma constante superação de limites pessoais e coletivos, para um aprimoramento do sujeito e da sociedade. Trata-se de atingir o melhor de si, para construir a melhor das sociedades, dialeticamente falando, segundo seu pensamento. Então, considerando a relevância do método de Paulo Freire no trabalho com a EJA, é importante que recordemos um dos seus primeiros feitos, que se deu junto à equipe do Serviço Social de Extensão Cultural da Universidade Federal do Recife, no estado de Pernambuco, por volta do ano de 1962: Freire conseguiu desenvolver a marcante experiência de Angicos, localizado no estado do Rio Grande do Norte, considerado um grande feito, por alfabetizar em 45 dias, trezentos trabalhadores daquela região. Essa experiência foi inspiradora de todo o seu trabalho futuro, segundo percebemos. É, sem dúvida, uma referência para nossos escritos neste breve texto. 
Foi a partir das experiências de Angicos, que o pensador empreendeu sua prática educativa quando exilado no Chile, nos EUA, na Suiça e na África. Ao escrever Educação como prática da liberdade, (2000a, p. 36), recorda Thiago de Mello (1965) em sua Canção para os fonemas da Alegria, quando diz no último verso: "canção de amor geral que eu vi crescer nos olhos do homem que aprendeu a ler". No Chile, Freire fortaleceu ainda mais suas conviç̧ões, no sentido de que ensinar é, também, ato de aprendizagem, quando desenvolveu práticas pedagógicas junto aos camponeses plantadores de videiras. Por onde passava, demonstrava preocupação com os que tiveram roubada a oportunidade de se alfabetizarem na infância.

Assim, propôs uma concepção pedagógica denominada Círculo de Cultura, na qual defende uma nova relação entre educadores e educandos.

Veja bem, se o alfabetizador não está, sobretudo, disposto a viver com o alfabetizando uma experiência na qual o alfabetizando diz a sua palavra autêntica, tendo, no alfabetizando, um criador da sua aprendizagem. Pois bem, esse é um princípio que eu acho fundamental. Agora, uma outra consequência disso, desse falar a e falar com: eu só falo com, na medida em que escuto também. "Eu só escuto na medida em que eu respeito, inclusive o que fala me contradizendo". (FREIRE, 1992, p. 5)

Comumente conhecido como O método de Paulo Freire, muito embora ele mesmo não gostasse desse tratamento e preferisse que fosse denominado como uma concepção pedagógica, o Círculo de Cultura é marcado pela interdisciplinaridade, por ter como centro os diversos sujeitos na sua complexidade cultural, afetiva, social e política.

Dessa forma, o seu desejo era descobrir os caminhos do aprendizado em conjunto com as populações oprimidas. A concepção pedagógica freireana insere no fazer científico os conhecimentos/saberes populares. Esses são diversos e se interconectam. Assim, em toda prática social, é possível partir deles e incorporá-los aos processos educativos, como podemos notar a partir da afirmação abaixo:

Mas eu tenho a impressão que poderia colocar a nós, e não a vocês, porque eu coloco a mim também alguns elementos, chamemos até de princípios. Esses princípios são válidos não apenas pra quem está metido com a alfabetização, mas pra quem está participando em qualquer tipo de pastoral. Não importa se está fazendo alfabetização de adultos ou trabalhando na pastoral operária, qualquer uma que seja. É válido até pra quem é médico e trabalha com o povo. (FREIRE, 1992, p. 2) 
Desse modo, os princípios assumidos por Freire contribuem para 0 desenvolvimento de sua pedagogia com os sujeitos envolvidos no processo de alfabetização. E a leitura da palavra, que é também uma leitura do mundo, só é possível ser entendida, quando se alfabetiza "com" e não "para" o sujeito.

Esse método de construir o conhecimento com os educandos se tornou uma referência central para os interessados na práxis freireana. Foi e continua hoje sendo estudado e praticado por educadores de diversas áreas do conhecimento. Alguns exemplos são os grupos de pesquisa no Brasil e em outros países que refletem bem essa realidade. Nos últimos anos, foram criados inúmeros deles em São Paulo, Santa Catarina e Juiz de Fora. O grupo Paradigmas do oprimido, de Juiz de Fora, se organizou em diversos subgrupos, cobrindo um campo extenso de temáticas e problemas vinculados aos oprimidos: um grupo iniciou um estudo sobre a Civilização e Sociedade do Oprimido; outro sobre a Educação e Pedagogia do Oprimido; um terceiro sobre a Cultura, Ética e Estética do Oprimido; e um quarto sobre a Ciência e Tecnologia do Oprimido. A última experiência iniciada em Juiz de Fora trata da música do oprimido. Isso demonstra que está havendo uma utilização dos princípios freireanos, nas diversas áreas do saber, tendo o Círculo de Cultura como metodologia de trabalho. Compreendemos que os referenciais freirianos são tratados e abordados de modo interdisciplinar, atualizando as leituras e interpretações, suscitando novos diálogos e interconexões com as mais diversas áreas.

Ao tratarmos da Educação de Jovens e Adultos com base nessa referência, precisamos responder uma questão que diz respeito a como se realiza o processo de ensino aprendizagem, de tal modo que aquele que aprende, durante o processo, descubra o caminho da criatividade para se tornar autônomo, embora necessite do apoio do educador que organiza com ele as atividades educativas. Daí a importância de se ter claro o significado do círculo de cultura, apresentado pelo próprio Paulo Freire (2000a).

De acordo com as teses centrais que vimos desenvolvendo, pareceu-nos fundamental fazermos algumas superações, na experiência que iniciávamos. Assim, em lugar de escola, que nos parece um conceito, entre nós, demasiado carregado de passividade, em face de nossa própria formação (mesmo quando se lhe dá o atributo de ativa), contradizendo a dinâmica fase de transição, lançamos o Círculo de Cultura. Em lugar de professor, com tradições fortemente "doadoras", o Coordenador de Debates. Em lugar de aula discursiva, o diálogo. Em lugar de aluno, com tradições passivas, o participante 
de grupo. Em lugar dos "pontos" e de programas alienados, programação compacta, "reduzida" e "codificada" em unidades de aprendizado. (p. 111-112)

É bem possível que as inúmeras incompreensões referentes a Paulo Freire tenham origem nas afirmações acima citadas. Dentre as diversas acusações produzidas por leituras rápidas do pensamento freiriano, consta a de ingenuidade. Tal acusação não procede, pois Freire, ao criar neologismos (SIMÕES, 2013), ou ao reiterar a necessidade de transformação da escola de seu tempo, o fazia por clareza epistemológica e não tratava das palavras meramente no sentido literal. Quando uma palavra não lhe dava o sentido que desejava, ele criava uma outra, para melhor explicar a realidade. É preciso entender mais profundamente o que ele queria dizer, quando afirmava a necessidade de se trocar Escola por Círculo de cultura. Não se trata da extinção da escola, mas de renová-la por dentro, com métodos capazes de proporcionar o desenvolvimento educativo a partir de outras perspectivas.

$\mathrm{Na}$ prática, se faz necessário observar que, mesmo em face dos limitadores apontados, o modo do fazer educativo vai sendo construído em experiências singulares, às vezes incorporadas, e outras fora dos ambientes institucionais. Não se trata, tão somente, de mecanismos didáticos, mas experimentos que trazem uma nova perspectiva pedagógica, cujo princípio fundador é o diálogo. Nesse sentido, não há receitas, pois muitos avanços pedagógicos hoje vivenciados em escolas nasceram de experiências populares, em que algum educador esteve envolvido, ou então, por inspiração nos princípios freireanos, grupos e educadores que propõem novos modelos e realizam a pedagogia freireana. Ou seja, no dizer de Gramsci (2000), o "velho" e o "novo" vão se interconectando, e o "novo" aparece quando ainda o "velho" está se pondo.

Paulo Freire, quando afirma que, em lugar do professor doador de conhecimentos, dever-se-ia existir o organizador dos debates, não desmerece o professor, tanto que, em obras posteriores como Professora sim, tia não (2002), ele continua utilizando o termo professor. Na verdade, o que ele preconizava é que o professor deve ser convidado a contribuir e facilitar a construção do conhecimento com o estudante, e não sobre ele. Dessa forma, segundo o pensador, é preciso superar com o estudante as suas ingenuidades, indo além do senso comum, levando em conta, para tanto, o entorno cultural, a história do Revista Educação Online PUC-Rio nº 14, p.39-53, ago./dez. de 2013. 
educando. Não se afirma com isso que agora o professor não precisa ser um profundo estudioso de sua área de conhecimento; ele continua sendo uma referência necessária. Por isso, conhecer, estudar e problematizar as diversas áreas nas suas diversas facetas é o que garante o processo educativo para além do senso comum. É preponderante afirmarmos que o centro do processo educacional passa pelo binômio professor-educando, e nenhum deles é mais ou menos central ou importante que o outro; um não existiria sem o outro. Há sim, no pensamento de Freire, a compreensão de que o processo pedagógico também precisa de direção pedagógica, ou seja, o professor é o responsável por organizar, por contribuir, para que as condições desejadas estejam dadas. Portanto, o processo pedagógico, para ele, não é espontâneo e nem autoritário, mas participativo, interativo, criativo e dinâmico, a partir da realidade do educando.

\section{A prática da alfabetização pela experiência}

$\mathrm{Na}$ teia de realidades, Paulo Freire vai construindo sua prática e combatendo com energia os modelos autoritários de educação que ele denominou de Educação Bancária. Propunha em substituição a esse modelo, a educação problematizadora, libertadora, quando o educando também possui os seus saberes, como posto em:

A primeira experiência foi realizada no Recife, com um grupo de cinco analfabetos, dos quais dois desistiram, no segundo ou terceiro dia. Eram homens egressos de zonas rurais, revelando certo fatalismo e certa apatia diante dos problemas. Completamente analfabetos. No $20^{\circ}$ dia de debates, aplicamos teste de medição de aprendizado, cujos resultados foram favoráveis (positivos). Nesta fase, trabalhávamos com epidiascópio ${ }^{6}$, por nos proporcionar maior flexibilidade na experiência. Projetávamos uma ficha, em que apareciam duas vasilhas de cozinha, numa escrita a palavra "açúcar", noutra "veneno". E abaixo: "Qual dos dois Você usaria para sua laranjada?" Pedíamos então ao grupo que tentasse ler a pergunta e desse a resposta oralmente. Respondiam rindo, depois de alguns segundos: "açúcar". O mesmo procedimento com relação a outros testes, como por exemplo, o de reconhecimento de linhas de ônibus e edifícios públicos. $\mathrm{Na}$ vigésima primeira hora, um dos participantes escreveu com segurança: "Eu já estou espantado comigo mesmo". (FREIRE, 2000a, p. 111-112, nota inserida por nós)

O educando, depois de introduzido no processo da alfabetização, toma consciência dos possíveis prejuízos em suas escolhas cotidianas, como

\footnotetext{
${ }^{6}$ Uma espécie de retroprojetor.

Revista Educação Online PUC-Rio nº 14, p.39-53, ago./dez. de 2013.
} 
temperar um suco ou envenenar-se, tomar um ônibus equivocadamente e outros. Nesse sentido, à medida que ele tem clareza dessas percepções, por nada aceitará a imposição de não saber ler e escrever. Lutará com "unhas e dentes" para aprender a decifrar os textos e contextos. Terá encontrado aquilo que se denomina motivo, por meio de um sutil incentivo. Daí a importância dos inúmeros escritos de Freire relativos à conscientização e libertação dos grupos oprimidos.

Como realizar a educação? Como proporcionar ao sujeito meios para superar suas concepções mágicas ou ingênuas? Como fazer avançar do cotidiano para uma prática libertadora? Como ajudá-lo a criar sua montagem de sinais gráficos? Como ajudá-lo a se inserir? O caminho seria por meio de um método ativo, dialogal, crítico, criticizador e participante. O diálogo aqui se nutre do amor, da humildade, da esperança, da fé, da confiança (FREIRE, 2000a). Como se pode constatar, o diálogo é, nessa concepção de educação, como uma espinha dorsal necessária, que perpassa todos os momentos na relação família, educador e educando.

Então, o Círculo de Cultura é um lugar do diálogo e pode ocorrer na comunidade, na cidade, no campo. O diálogo é, para Paulo Freire, mais do que um instrumento da comunicação humana, constituindo-se em verdadeira categoria de razão dialético-dialógica, pois leva em conta as diferenças, os conflitos e se nutre do profundo respeito ao outro. O Círculo de Cultura não se detém somente nos primeiros momentos das palavras geradoras $\mathrm{e}$ decodificações das mesmas: trata-se de um aprendizado para a vida. Uma vez internalizada a práxis dialético-dialógica, as relações com os significados, conteúdos, vivências e experiências sofrem um salto qualitativo, o que Freire reconhecia como a superação da consciência oprimida.

No Círculo de Cultura, não se negam os conflitos, mas se busca acolhêlos e dar-lhes encaminhamentos. O conhecimento é circular, se completa com a participação de cada membro do grupo social. Nesse sentido, a proposta pedagógica freireana ultrapassa uma mera técnica e passa a ser compreendida a partir da experiência prática de cada um. É, pois, perceptível a importância dessa visão na construção de um processo educativo humanizador. 
Não são poucos os analfabetos que aprenderam, a partir de seu meio, uma espécie de desvalorização de si mesmos, já que se reconhecem como sujeitos não possuidores de direitos e deveres. Nutrem-se do sonho de um dia ter algum bem material, social, mas não se julgam merecedores. Alguns hospedam em si o germe da negação de si, pois pensam com a cabeça do opressor. Mas, na medida em que se libertam, não conseguem mais voltar atrás. Isso Freire chama de libertação.

E esta luta somente tem sentido quando os oprimidos, ao buscarem recuperar sua humanidade, que é uma forma de criá-la, não se sentem idealistamente opressores, nem se tornam de fato, opressores dos opressores, mas restauradores da humanidade em ambos. (FREIRE, 2000b, p. 30)

Dessa forma, em diversas circunstâncias, passamos por experiências que nos fazem nos sentirmos analfabetos, como aquelas em que nos deparamos diante de uma tribo indígena, ou de pessoas que falam línguas ou dialetos diferentes dos nossos, ou, às vezes, diante de códigos quase indecifráveis da linguagem econômica, biológica, sociológica e outras. Isso nos dá uma pequena noção do que seria a vida do analfabeto, com o agravante de que ele não consegue ler e compreender o que se passa no cotidiano. Essa consciência é fundamental para quem trabalha com a EJA. É nessa perspectiva, que defendemos um conteúdo que se adapte às necessidades do educando, por considerarmos que a relação de aprendizagem passa por mediações institucionais, cotidianas, políticas, culturais vivenciadas de modo interdisciplinar. A EJA se propõe a catalisar essas dinâmicas, com a finalidade de proporcionar o que vemos na fala de um analfabeto: "Quero aprender a ler e a escrever para mudar o mundo" (FREIRE, 2000a, p. 121). É, pois, um estado de consciência necessário a todo ser humano.

Daí nasce a necessidade de interferir, transformar e modificar o mundo, pois já modificou a si mesmo, a sua compreensão de mundo, já transformou o seu ver e agora modifica o seu agir, que não cabe mais nos estreitos conceitos, pela qualidade imóvel dos mesmos. Quem conhece, experimenta novos desejos e contribui para o crescimento do outro nas diversas dimensões da vida. Ao conhecer, empodera-se de algo propulsor da vida nas suas diversas dimensões. Nesse sentido, não há um tempo definido para se aprender. A todo instante e em todas as idades, é hora de aprender, porque o aprendizado gera, sustenta e 
contribui para mudanças de atitudes, de compreensão, mobilizando para transformações.

O Círculo de Cultura busca problematizar a condição complexa da vida, de tal modo que "as palavras geradoras deveriam sair destes levantamentos e não de uma seleção que fizéssemos nós mesmos, em nosso gabinete, por mais tecnicamente bem escolhidas que fossem" (FREIRE, 2000a, p. 121). Isso significa que, ao construir o conteúdo a ser trabalhado com o educando, em forma de problematização de sua história de seu chão, no contexto cultural de sua existência, não se escolhe uma temática ou palavras, porque o facilitador considera a melhor, mas aquela(as) que expressa $(\mathrm{m})$ melhor a real condição dos sujeitos. Tudo isso nos leva a uma nova compreensão da educação como um esforço para contribuir com a libertação, e não mais para a dominação, uma vez que

É a prática que vai determinando, é a práxis que institui alguém como sujeito cognoscente, independentemente até do sujeito. Mas, naquela época, eu me perguntava, por exemplo, às vezes inteiramente só na minha saleta de estudos: será que a alfabetização de adultos, diria agora simplesmente alfabetização, é uma experiência na qual o alfabetizador instrumentaliza o alfabetizando, dandoIhe de graça os ba,bé,bi,bo,bu; os la,le,li,lo,lu? Não, não pode ser. A alfabetização é um ato de conhecimento, dizia eu naqueles anos, e anos depois volto e torno a dizê-lo. (FREIRE, 1985, p. 46)

Dessa forma, o ato de conhecer é essencialmente relacional e contribui para que o educando saia de si em busca do outro. A alfabetização freiriana indica essa perspectiva como um possível caminho para a introdução do educando no mundo.

\section{Alfabetização: práxis, ato político e produção coletiva}

Pensando a alfabetização como um ato político e de conhecimento, podemos observar algo em Paulo Freire, que nos faz pensar como, na prática, ele transformou até mesmo o modo de realizar suas publicações. Antes escrevia livros sozinho e, a partir de um certo momento de sua vida, passou a dialogar com autores de diversas partes do planeta. Escreveu com importantes autores mundiais, como observamos na transcrição de um seminário no qual se tratou do processo educativo de Freire e Rivière, quando foram aprofundadas as concepções do Círculo de Cultura e do sentido da educação de adultos não instrumentalizadora e nem doadora de conhecimentos. 
A práxis freiriana, é, portanto, coletiva e, ao articular as dimensões teóricoprática e prático-teórica, se realiza no combate aos voluntarismos e espontaneísmos, muito comuns em ambientes que se utilizam da educação com outros fins que não os de educar. É um processo político pedagógico que faz uma crítica objetiva ao mundo capitalista e ao poder político, quando esses protelam o acesso aos direitos pelos oprimidos, produzindo conformismo social. "Precisamos estar convencidos de que o convencimento dos oprimidos de que devem lutar por sua libertação não é doação que Ihes faça a liderança revolucionária, mas resultado de sua conscientização" (FREIRE, 2000b, p. 54).

Não é pouco comum encontrarmos grupos sociais que, mediante tais violências, se acomodem e perdem a perspectiva da transformação social. $\mathrm{O}$ processo de reificação é tão frequente, que passa a turvar a compreensão dos oprimidos, que já consideram não existirem possibilidades de avançarem e transformarem o meio em que vivem. Esperam por um futuro, mas não transformam o hoje. A utopia necessita alimentar-se do hoje, em um permanente engajamento no que está sendo, para que ocorra um devir do que se deseja. Nesse sentido, o educando necessita estar desejoso de aprender a ler, escrever e a interpretar o seu mundo.

Uma compreensão do significado mais profundo de cultura, no trato com o analfabeto, se torna, aqui, tema de grande relevância. Assim, o educando necessita compreender $\circ$ valor da cultura popular, para também autocompreender-se como sujeito educando e educador. É fundamental considerarmos que nenhum povo é superior a outro, embora saibamos que aqui e acolá, em algumas nações, existam governantes ou grupos que se consideram culturalmente superiores, mas que não o são.

Não se trata de negarmos ou meramente criticarmos o saber científico ou popular, mas afirmar a importância da troca dos saberes, pois não existem pessoas ou grupos sem cultura. Deixar de ser "coisificado" é uma conquista fundamental para aqueles e aquelas que não dominam a escrita. Torna-se fundamental que o sujeito consiga realizar uma leitura de mundo que preceda a leitura da escrita, pois o analfabetismo político é mais grave do que não saber ler e escrever, embora ambos devam ser combatidos e superados,

"Quero aprender a ler e a escrever", disse uma analfabeta do Recife, "para deixar de ser sombra dos outros". E um homem de Florianópolis, revelando o processo 
de emersão do povo, característico da transição brasileira: "O povo tem resposta”. Um outro, em tom magoado: "Não tenho 'paixão' de ser pobre, mas de não saber ler". (FREIRE, 2000a, p. 121)

A partir do momento que o educando tem esta clareza, ele está preparado e conscientizado do seu lugar no mundo, e, assim, se constrói a sua verdadeira identidade de sujeito de sua história. Paulo Freire manteve sempre no horizonte de sua orientação a necessidade de transformar as relações de classe, o que significa dizer a necessidade de formar os trabalhadores, para que compreendam a realidade em que vivem e como interferir na mesma.

\section{Alfabetização como ato político}

$\mathrm{Na}$ ação de alfabetizar, não é possível separar a formação mais profunda do educando. Ele necessita compreender que a cidadania negada deve ser conquistada. Podemos perceber que essa visão de Paulo Freire está mais bem desenvolvida na Pedagogia do oprimido (2000b). Reiteramos que a problematização apresentada aqui se adapta a qualquer um dos momentos escolares dos educandos, pois se trata de fazer uma pedagogia do oprimido e não uma pedagogia para o oprimido. A situação de opressão pode-se dar também em qualquer circunstância da vida ou na relação escolar.

Ao escrever a pedagogia do oprimido, Paulo Freire contribuiu para uma nova visão entre educador e educando. Para o pensador, o educador deve estar constantemente atento, para que, ao ensinar, seja também capaz de aprender com seu educando. Trata-se de uma relação de aprendizagem mútua, ao mesmo tempo em que a relação não pode ser de subserviência, mas de colaboração entre educador e educando. Daí a afirmação de Freire sobre o processo educativo: "ninguém liberta ninguém, ninguém se liberta sozinho: os homens se libertam em comunhão" (2000b, p. 52). É necessário, pois, que entendamos que a libertação não é algo realizado por terceiros ou por quem quer que seja, a libertação verdadeira é aquela em que o sujeito se liberta em conjunto com a sua comunidade. Na medida em que o oprimido percebe a importância de sua decisão de romper com a desumanização, desencadeia-se um processo de transição e libertação, um trânsito de consciência.

Há um quadro de Freire que vale a pena ser citado na íntegra, dado a sua intencionalidade, o que nos ajuda a compreender o que ele pensava sobre a 
educação bancária e educação problematizadora, e o que se deve aceitar ou rejeitar no processo educativo:

a) O educador é o que educa; os educandos, os que são educados;

b) O educador é o que sabe; os educandos, os que não sabem;

c) O educador é o que pensa; os educandos, os pensados;

d) O educador é o que diz a palavra; os educandos, os que a escutam docilmente;

e) O educador é o que disciplina; os educandos, disciplinados;

f) O educador é o que opta e prescreve sua opção; os educandos, os que seguem a prescrição;

g) O educador é o que atua; os educandos, os que têm a ilusão de que atuam, na atuação do educador;

h) O educador escolhe o conteúdo programático; os educandos, jamais ouvidos nesta escolha, se acomodam a ele;

i) O educador identifica a autoridade do saber com sua autoridade funcional, que opõe antagonicamente à liberdade dos educandos; estes devem adaptar-se às determinações daquele;

j) O educador, finalmente, é - o sujeito do processo; os educandos, meros objetos. (FREIRE, 2000b, p. 59)

Assim, não é mais possível trabalhar no campo da EJA, imaginando que o educando adulto se apresente meramente a partir dessa condição. Ele não é depósito e nem receptáculo de conhecimentos emanados do professor. Não é meramente um ser de adaptação ou de ajustes. Não é menos e nem é mais: está no seu momento privilegiado de dar continuidade a seus aprendizados, o que, de algum modo faz parte, de sua constituição ontológica, um ser que aprende permanentemente na direção de uma libertação pessoal e coletiva.

Os modelos autoritários e bancários de educação não tiveram outro movimento, senão trabalhar para inverter o sentido da existência humana, que ontologicamente existe para a diversificação, para a busca de ser mais, não domesticável. A situação de aprendizado é permanente e deve fazer parte da cotidianidade do sujeito construtor de si mesmo e não subjugado, escravizado, domesticado. Sua vocação não é para ser coisa, daí não aceitar o processo de 'desgentificação'. A educação libertadora se move na direção da vida e do amor, para o pensamento freireano?

Freire (1993), em sua consistente visão política, afirmou que "educação é um ato político" na medida em que localiza o sujeito espaço-temporalmente. Assim, estar no mundo é diferente de passar pelo mundo, tanto quanto viver é

\footnotetext{
${ }^{7}$ O sentido de vida e amor em Freire se estabelece na relação de superação da opressão. Buscar os direitos dos oprimidos é um ato político movido por um profundo ato de amor.

Revista Educação Online PUC-Rio no 14, p.39-53, ago./dez. de 2013.
} 
diferente de vegetar. O desafio de uma educação crítica e avançada está exatamente no quanto ela permite a reflexão do sujeito sobre si em relação com o conjunto das demais dimensões sociais.

A realidade é por si mesma interdisciplinar, e os processos pedagógicos que conseguem recuperá-la permitem que a aprendizagem se torne ato político, pois insere o educando-educador no conjunto de relações que o produzem e que podem ser modificadas por ele.

\section{Referências bibliográficas}

BRANDÃO, Carlos Rodrigues. O que é Método Paulo Freire. São Paulo: Brasiliense, 1981.

popular. São Paulo: Brasiliense, 1984.

(Org.). A questão política da educação

Paulo: UNESP, 2005.

Paulo Freire, o menino que lia o mundo. São

FREIRE, Paulo. Cartas a Cristina: reflexões sobre minha vida e minha práxis. São Paulo: Paz e Terra, 2003.

. Política e educação. São Paulo: Cortez, 1993.

- Cartas a Guiné-Bissau: registros de uma experiência em processo. $4^{\text {aed. }}$ Rio de Janeiro: Paz e Terra, 1984.

. A televisão educativa. Entrevista concedida ao Instituto PichonRivière de São Paulo. São Paulo: Vozes, 1985. p. 46-48.

Terra, 2000a. . Educação como prática da liberdade. $24^{\mathrm{a} e d}$. São Paulo: Paz e

Capacitação da Juventude, 1992.

- Para trabalhar com o povo. $2^{\mathrm{a} e d}$. São Paulo: Centro de . Pedagogia do oprimido. Rio de Janeiro: Paz e Terra, 2000b.

. Professora sim, tia não: cartas a quem ousa ensinar. São Paulo: Editora Olha d' Água, 2002.

GRAMSCI, Antonio. Os intelectuais. O princípio educativo. Jornalismo. Rio de Janeiro: Civilização Brasileira, 2000. Vol. II.

MELLO, Thiago. Faz escuro mas eu canto. Rio de Janeiro: Civilização Brasileira, 1965.

ROMÃO, José Eustáquio et al. Educação \& Linguagem, Ano 9, $\mathrm{n}^{\circ} 13$, jan-jun 2006. 